DOI: $10.17805 /$ zpu.2017.1.8

\title{
Две роли человека в «спектакле культуры»
}

\author{
А. Я. ФЛИЕР \\ РОССИЙСКИЙ НАУЧНО-ИССЛЕДОВАТЕЛЬСКИЙ ИНСТИТУТ \\ КУЛЬТУРНОГО И ПРИРОДНОГО НАСЛЕДИЯ ИМ. Д. С. ЛИХАЧЕВА
}

В статье интерпретируется сложная система соотношений культуры и идеологии, публичные и приватные варианты актуальной идеологии, культуры, идентичности человека, фрагментированное состояние его сознания. Особо анализируются две роли, исполняемые индивидом ситуативно в процессе социокультурных взаимодействий с окружением «человека публичного» и «человека приватного». При этом культура личности трактуется как высоко театрализованная программа поведения, преследующая цели поддержания конструктивных отношений с властью и непосредственным социальным окружением.

Рассматриваются культурные установки человека как имманентные формы внутренней нравственной идеологии личности, культура общества как спектакль социальных взаимодействий членов этого общества, а также роль культуры и идеологии в историческом процессе эволюции, в числе иных “локомотивов истории», определяющих динамику изменчивости социального устроения сообществ.

Основная идея статьи заключается в том, что культура общества может толковаться как форма господствующей идеологии (если понимать последнюю не только в политическом ключе), но индивид в разных социальных ситуациях выступает с разными идеологическими императивами, которые, как правило, определяются его ролями «человека публичного» и «человека приватного», с чем связан и феномен множественной идентичности современного человека, и иные фрагментированные проявления его сознания.

Ключевые слова: культура; идеология; человек публичный; человек приватный; множественная идентичность; идеологическая фрагментарность; профессиональная специализация; спектакль социальных отношений

\section{ВВЕАЕНИЕ}

$\mathrm{K}$ числу наиболее обсуждаемых гуманитарной наукой «вечных проблем» относится вопрос о том, что является основным «локомотивом истории», т. е. двигателем динамики социального развития, а также культурной изменчивости как отражения этой динамики. Нам хорошо известны эволюционные концепции развития. Например, 
формационная модель К. Маркса, полагавшего, что развитие происходит благодаря накоплению социальных противоречий и их революционному разрешению (Маркс, 1959). Признаюсь, что мне ближе концепция Э. Аюркгейма, усматривавшего источник социальной динамики в нарастающих процессах разделения труда и его специализации (Аюркгейм, 1991). Сейчас наиболее авторитетны взгляды футурологов второй половины XX в., полагавших, что основной причиной социального развития являются технологические новации в продуктивной деятельности передовых сообществ (Белл, 1999; Тоффлер, 1997; Фукуяма, 2004; Touraine, 1969). Разумеется, в науке распространены и принципиально иные, неэволюционные трактовки социальной динамики (например, циклическая), но они не имеют отношения к проблематике настоящей статьи и сейчас рассматриваться не будут.

Что же касается эволюционных концепций развития, то в первую очередь необходимо отметить тесную связь всех упомянутых причин социальной динамики. Технологические новации способствуют ускорению процессов разделения труда, что в свою очередь стимулирует канализацию профессиональных интересов и возрастание социальных противоречий. Одно вытекает из другого. Можно спорить о том, что является главной причиной, а что ее следствием. Мне представляется, что в разных конкретных исторических ситуациях под влиянием внешних или внутренних факторов имело место доминирование разных пусковых механизмов динамики. Но это не оказывало принципиального влияния на конечный результат, на прогресс в области социального устроения сообществ. Под прогрессом я понимаю бо́льшую рациональность этого социального устроения, соответствующую уровню развития материально-производственных, интеллектуальных и социальных технологий.

А основное различие этих эволюционных концепций заключается в научном удобстве описания и объяснения того или иного процесса, интересующего ученого. Например, я рассматриваю историческую динамику социального развития в рамках технологической концепции, где это развитие выглядит более системным. А вот причины социальной динамки я предпочитаю объяснять в рамках дюркгеймовской концепции разделения труда, для меня более операциональной. Но я признаю достоинства и марксистской революционной концепции, только не абсолютизирую ее; эта модель, как и все другие, объясняет часть исторических реалий, а не всю историю. На самом деле, по моему мнению, речь идет о разных вариациях одной и той же объяснительной схемы, привязывающей социальное развитие к продуктивной деятельности людей.

Основной вопрос этой статьи: как осуществляется перерастание социальной динамики в культурную? Мне представляется, что это происходит при посредничестве идеологии. Хотя какую-то часть своих целеориентированных действий человек исполняет в автоматическом режиме, не концентрируя внимания на этом, но все-таки основная масса культурно обусловленных акций осуществляется им сознательно, в режиме ориентации на те или иные правила или образцы.

\section{КУАБТУРА КАК ИАЕОАОГИЯ}

Культура в определенном смысле является внутренней поведенческой идеологией личности, определяющей нормы осуществления социальной практики. Аюбую деятельность в принципе можно исполнять по-разному. Но в культуре каждого народа исторически сложились некоторые принципы или традиции, требующие осуществлять те или иные действия именно так, а не иначе. Причины сложения этих установок различ- 
ные, иногда определенно рациональные, иногда рационально не объяснимые. Но сам факт предпочтения одних принципов практической деятельности, межличностного взаимодействия и коммуникации другим является именно культурной идеологией.

Понятие «идеология» характеризуется многими определениями в широком аксиологическом диапазоне от явно негативных ( «предвзятое отражение социальной действительности», «готовый “мыслительный товар”, распространяемый прессой, ораторами, идеологами для того, чтобы манипулировать массой людей» и т. п.) до относительно нейтральных ( «взаимосвязанная система идей», «выражает специфические интересы определенного класса», «идеологии не “истинны” и не “ложны”, но являются релятивистскими интеллектуальными стратегиями для категоризации мира» и пр.) (подробней об этом см.: Идеология, 1952). Впрочем, в данном случае нас интересует не сравнение различных подходов к этому понятию, а рассмотрение соотношения идеологии и культуры.

Государственная идеология так или иначе влияет на все области культуры общества, но особенно она связана с политической организацией, с принципами политического устроения. В этом вопросе идеология является квинтэссенцией актуальной политической теории. Необходимо отметить, что идеология уделяет особое внимание исторической памяти народа, устанавливая, что следует прославлять в истории, а что осуждать. Именно она трактует прошлое как исторический прецедент современных политических решений. Вместе с тем государственная идеология является наименее устойчивым сегментом культуры общества, часто определяясь субъективными предпочтениями того или иного правителя и меняясь со сменой людей у власти. Исторических примеров тому мы знаем множество. В любом случае, идеология, будучи официальной или альтернативной, представляет собой свод определенных ценностных установок, регулирующих социальную практику людей в соответствии с целями власти, взглядами оппозиции или позицией независимых интеллектуалов, не поддерживающих ни то, ни другое.

Здесь стоит упомянуть основоположника неомарксизма А. Грамши и его теорию гегемонии. В ней утверждается, что историческая устойчивость капитализма базируется не только на его экономической әффективности, но и на том, что он создает культуру и идеологию, абсолютно доминирующие в сознании народной массы, которым она (масса) не в состоянии противопоставить конкурентоспособную культурную альтернативу (Грамши, 1959). Тут многое зависит от интеллигенции, поскольку современную культуру создает именно она. И историческая устойчивость политической идеологии, как правило, зависит от того, комфортна ли она для интеллигенции или побуждает ее к «внутренней эмиграции». Во втором случае идеология не переживет своего креатора.

Ао сих пор мною рассматривалась только политическая идеология, определяющая взаимоотношения власти с населением страны. Но идеологией можно считать и любую системно сформулированную культурную стратегию, касающуюся взаимодействий (взаимоотношений) одного человека с другими людьми. Например, семейные люди нередко разрабатывают идеологию семейных отношений, на основе которой осуществляется семейная политика. Точно так же может иметь место идеология взаимоотношений человека с друзьями, соседями, коллегами и пр. Но это все идеологии «человека приватного». Идеология «человека публичного» всегда касается прямых или опосредованных (иногда очень опосредованных) отношений с властью и ее представителями или с каким-то начальством (по службе, месту проживания и т. п.). 
Нет сомнений в том, что культура и идеология родственны: в каком-то смысле идеология представляет собой развитие базовых установок (ценностей) культуры в более практическом плане и доведение их до определенной крайности. Иными словами, то, что культурой только рассматривается как ценностное допущение (потенциальная возможность), идеологией постулируется как прямое руководство к действию.

Впрочем, на деле все гораздо сложнее. На первый взгляд бо́льшая часть населения всякого государства придерживается доминирующей идеологии, и лишь какие-то маргинальные группы склонны к альтернативным воззрениям. Но реально большинство людей ориентировано как минимум на две, а иногда и большее число идеологий в зависимости от ситуации. Как правило, в каждом человеке уживаются две культурно-идеологические ориентации, проявления которых можно назвать «человек публичный» и «человек приватный».

Если в первобытную эпоху кроме основной мифоритуальной идеологии не существовало никаких иных идеологий (а стало быть, и культурных стратегий), то в агарную эпоху ситуация изменилась. Например, средневековой крестьянин как «человек публичный» ходил в церковь, был верным слугой своего барина, а если требовалось, то и монарха, но как «человек приватный» в своей бытовой хозяйственной жизни, взаимоотношениях с семьей, соседями он был выразителем совсем иной культуры и идеологии, построенных на традиционных обычаях. В свою очередь обычаи вели свое происхождение еще из родо-племенных порядков и плохо сочетались с официальными церковными и светскими нормами, с чем церковь и власть последовательно боролись, но успеха в этом не достигали (проще было адаптировать официальные нормы к устойчивым обычаям). Точно так же и горожанин аграрной әпохи как «человек публичный» был лояльным обывателем, вполне мистифицированным официальной идеологией и исполнявшим ее ритуалы, а как «человек приватный» придерживался более прагматичной идеологии и протобуржуазной культуры третьего сословия, существовавшей параллельно с феодальной иерархической культурой средневекового города. Еще противоречивее была ситуация с аристократией; здесь все зависело от близости к власти. Аля аристократа, входившего во властную элиту, видимо, большого отличия его публичной культуры и идеологии от приватной не было. А вот аристократ, далекий от власти, соблюдая все условности публичной лояльности монарху, предавался разным приватным шалостям, и в его идеологии прослеживались истоки будущего либерализма.

Таким образом, уже в аграрную эпоху мы видим культурно-идеологическую фрагментированность сознания значительной части населения, культурное различие между масками «человека публичного» и «человека приватного» у большинства людей. Это вовсе не значит, что в своей публичной маске человек был неискренен. В нем уживались две культуры и две идеологии, применимые к разным жизненным ситуациям, над альтернативностью которых он, как правило, не задумывался.

Это еще больше усилилось и обострилось в индустриальную эпоху. Все мы прекрасно помним, как еще недавно в советское время мы аплодировали на официальных собраниях произносимым политическим догмам, а затем, сидя на кухне, ёрничали над чушью, которой только что аплодировали. В западных странах этот разрыв между публичной и приватной жизнью человека был не таким острым, но на деле он имел место и там. Во всяком случае, понятия «человек публичный» и «человек приватный» родились именно в западноевропейской социологии на основании анализа социальных реалий Запада (Сеннет, 2002). Культурно-идеологическое расхождение между «человеком публичным» и «человеком приватным»в индустриальную эпоху всюду 
было актуальным, только у нас оно тщательно скрывалось, а на Западе никто из него тайны не делал, но и особого внимания на это не обращал.

Как обстоят дела с этим вопросом ныне, в постиндустриальную эпоху, судить рано.

Культурно-идеологическая ситуация в современной России напоминает советскую. По телевизору ведется непрерывная пропаганда официальной этатистской идеологии, превозносящей государство как оптимальную форму социальной организации над обществом - продуктом либеральных идей. Население, как правило, воспринимает все это равнодушно (есть основания полагать, что в социологических опросах по старому советскому опыту люди неискренни в выражении своей единодушной лояльности). А фактически интеллигенция в своем кругу придерживается в основном идеологии либерализма, молодежь склонна преимущественно к национализму (в разных вариантах: от умеренного традиционализма до крайностей неонацизма), старшее поколение ориентируется, как правило, на разные варианты социалистической (коммунистической) идеологии и т. п. Убежденными этатистами (государственниками-патриотами) в основном являются люди, связанные с властью, әкономически от нее зависящие, а еще больше психологически зависимые от государственного патернализма (еще одна советская привычка во всем рассчитывать на государство, а не на самих себя). Независимые интеллектуалы предпочитают отмалчиваться. Налицо выраженная культурно-идеологическая фрагментированность сознания основной массы населения, мало отличающаяся от советской.

\section{ФРАГМЕНТИРОВАННОСТЬ СОЗНАНИЯ}

В этой связи нужно вспомнить и о феномене множественной идентичности, горячо обсуждаемом социологами и этнологами (Аанилова, 2005; Климов, 2001; Малахов, 1999; Малыгина, 2002; Ядов, 1994). Она связана со сложностью многих современных социальных и национальных проблем, с обилием национально смешанных браков, с возросшей миграцией и т. п. На самом деле и здесь описывается идентификационный раскол в самосознании современного человека, связанный с необходимостью все время менять маски, выступая то «человеком публичным», то «человеком приватным». На мой взгляд, и здесь речь идет об одном из проявлений той фрагментированности культурно-идеологического сознания, о котором говорилось выше. Современный человек, выступая то в качестве «человека публичного», то «человека приватного », в различных сменяющихся ситуативных контекстах манифестирует себя с разной идентичностью, более удобной для того или иного контекста, в разных ситуативных культурно-идеологических ролях (Сеннет, 2002; Флиер, 2012, 2013).

Если феномен подобной фрагментированности социального сознания человека имеет столь глубокие исторические корни, то, естественно, возникает вопрос, откуда он взялся. И вот здесь необходимо опять вернуться к Э. Аюркгейму и его исследованию динамики возрастания разделения труда и углубления специализации (Аюркгейм, 1991). Профессиональная деятельность крестьян и ремесленников аграрной эпохи носила в большой мере семейный характер; в ней участвовали отец семейства и его взрослые сыновья, перенимавшие у отца секреты мастерства. Но в индустриальную әпоху углубление специализаций зашло столь далеко, что домашнее обучение стало уже неэффективным. Профессиональное обучение потребовало создания специализированных учебных заведений, дающих подготовку на уровнях как высшего, так и среднего профессионального образования. Аети уже не повторяли практику отцов, а в основном стали свободны в выборе сферы своей социальной самореализации. 
Соответственно, профессиональная и приватная (семейная) культуры человека стали удаляться друг от друга с каждым поколением все сильнее и сильнее.

Одновременно и взаимосвязано с этим процессом происходило размежевание публичной и приватной культур. Публичная культура (а с ней и идеология этого сегмента жизни) стала все больше зависеть от экономических обстоятельств существования общества, глубины профессиональной специализированности людей, социальной мобильности человека, уровня развития демократии и т. п., а приватная культура оставалась в рамках прежней идеологии, ориентированной на систему традиционных обычаев, хотя какое-то развитие в ней тоже имело место. Культурно-идеологическая фрагментированность сознания человека усиливалась и здесь, и маски публичного и приватного человека все сильнее различались между собой.

Согласно современным научным представлениям любые социальные отношения (как публичные, так и приватные) высоко театрализованы и представляют собой некие социальные спектакли с определенными типовыми ролями, масками, стандартными социальными коллизиями и т. п. (Аебор, 2000). Но публичные и приватные отношения - это разные спектакли, решающие разные задачи социального взаимодействия и базирующиеся на разных сценарных основах. Безопасные отношения с властью и комфортные отношения с близким социальным окружением основываются на разных типах поведения человека и его культурных образах, расхождение между которыми от эпохи к эпохе увеличивается. Впрочем, я полагаю, что и вся культура как программа обеспечения коллективного характера жизнедеятельности - это в определенном смысле спектакль сочиальных взаимодействий, очень сложный по своей драматургии и сценографии, разнообразный по разыгрываемым сюжетам, а главное - огромный по количеству занятых в нем людей.

Какое все это имеет отношение к «локомотиву истории», с рассуждения о котором начиналась эта статья? Таким «локомотивом», как уже говорилось, я полагаю процессы развития технологий и углубления специализированности человеческой деятельности. Но любая коллективная деятельность, обеспечиваемая культурой, подразумевает и активные социальные взаимодействия. И вот здесь важную организующую роль начинает играть идеология. Именно идеология, задающая сценографию спектаклям публичной и приватной жизни человека, выполняет функцию системы светофоров и дорожных указателей на пути этого «локомотива истории». Разумеется, в ходе истории идеология неоднократно меняется, а с ней меняется и вся система дорожных указателей.

А в более широком понимании - это и есть культура и ее историческая динамика. Существенная часть того, что мы понимаем под историей, по существу, есть совокупность артефактов культурной динамики. Вопрос лишь в масштабе истолкования культуры. Если в культуре видеть практическую реализацию идей и намерений людей, не преследующих непосредственную прагматическую пользу (этим занимается экономика), а опредмечивающих (воплощающих в материальных продуктах, текстах и организационных формах) определенные ценностные установки сознания, то история и ее события состоят в большой мере из культурно детерминированных действий людей. Тем более культурно детерминирована их идеология.

\section{ЗАКАЮЧЕНИЕ}

Вопрос о том, насколько социальные процессы проявляются в культурных формах, остается научно дискуссионным. Я полагаю, что все социальное проявляется 
внешне через культурное. Отсюда моя сентенция «все культурное социально, и все социальное культурно» (см.: Флиер, 2016). Конечно, есть еще и индивидуальная культура отдельного человека. Но она-то как раз и демонстрирует уровень социализированности этого человека, его включенности в нормы социальных взаимодействий. Поэтому и идеология как общества, так и отдельного человека фактически является частью культуры этого общества и этого человека, и фрагментированность их сознания одновременно относится и к идеологии, и к культуре.

Социальное развитие (как в форме революции, так и в форме эволюции) представляет собой взрывное порождение новых культурных форм, среди которых важнейшей является новый организационный принцип социального устроения общества, расширяющий пространство әффективной деятельности личности. Новые культурные формы, как правило, более рациональны, чем прежние. Но новые культурные формы мало просто создать, их нужно еще внедрить в массовое пользование. Основным механизмом такого внедрения является новая идеология. Так что социальное развитие обязательно проявляется в новых культурных формах и новой идеологии.

Из этого вовсе не следует тождественность культуры и идеологии. Если понимать культуру как драму социального бытия, то идеология только ее часть; сюжетная интрига этой драмы. Но в драме, кроме сюжетной интриги, еще есть система образов, психология персонажей, символика отдельных фраз, жестов, телодвижений и т. п. Однако основная сюжетная интрига задает общий контекст понимания всего остального. Поэтому научное исследование культуры как системы параллельных и нередко противоречащих друг другу идеологий «человека публичного» и «человека приватного» представляется мне вполне релевантным и, безусловно, очень интересным аналитическим ракурсом.

\section{СПИСОК АИТЕРАТУРЫ}

Белл, А. (1999) Грядущее постиндустриальное общество : пер. с англ. М. : Академия. 578 с.

Грамши, А. (1959) Избранные произведения : в 3 т. М. : Издательство иностранной дитературы. Т. 3. 371 с.

Аанилова, Е. Н. (2005) Социальные идентификации в трансформирующемся обществе // Социальные трансформации в России: теории, практики, сравнительный анализ / под ред. В. А. Ядова. М. : Флинта. 583 с. С. 324-364.

Аебор, Г. (2000) Общество спектакля. М. : Аогос-Радек. 184 с.

Аюркгейм, Э. (1991) О разделении общественного труда. Метод социологии : пер с. фр. М. : Наука. 575 с.

Идеология (1952)// Большая советская энциклопедия : в 51 т. / Б. А. Введенский. 2-е изд. М. : Советская энциклопедия. Т. 17. 632 с. С. 333-337.

Климов, И.Е. (2001) Персональные механизмы возникновения кризиса идентичности // Трансформация идентификационных структур в современной России / под ред. Т. Г. Стефаненко. М. : Московский общественный научный фонд. 218 с. С. 54-81.

Малахов, В. С. (1999) Ностальгия по идентичности // Иогос : философско-литературный журнал. № 3. С. 8-12.

Малыгина, И. В. (2002) В лабиринтах самоопределения: опыт рефлексии на тему этнокультурной идентичности. М. : МГУКИ. 282 с.

Маркс, К. (1959) К критике политической экономии // Маркс, К., Энгельс, Ф. Соч. : в 50 т. 2-е изд. М. : ИПА. Т. 13.765 с. С. 1-167.

Сеннет, Р. (2002) Падение публичного человека. М. : Аогос. 424 с.

Тоффлер, Э. (1997) Футурошок : пер. с англ. М. : Аань. 464 с. 
Флиер, А. Я. (2013) Культурные роли в процессах социального действия // Вопросы культурологии. №1. С. 12-19.

Флиер, А. Я. (2012) История культуры как смена доминантных типов идентичности // Аичность. Культура. Общество. Т. 14. Вып. 1 (69-70). С. 108-122; Вып. 2 (69-70). С. 99-108.

Флиер, А. Я. (2016) Опыт моделирования культуры как социальной системы // Знание. Понимание. Умение. № 2. C. 113-124. DOI: 10.17805/zpu.2016.2.10

Фукуяма, Ф. (2004) Конец истории и последний человек : пер. с англ. М. : АСТ ; Ермак. 488 с.

Ядов, В. А. (1994) Социальная идентификация в кризисном обществе // Социологический журнал. № 1. С. 35-52. $315 \mathrm{p}$.

Touraine, A. (1969) La Societé post-industrielle. Naissance d'une société. Paris : Denoël Gonthier.

Аата поступления: 07.12.2016 2.

TWO ROLES OF THE MAN IN THE «CULTURE PERFORMANCE»

A. A. FLIER

D. S. LIKHACHEV RUSSIAN RESEARCH INSTITUTE FOR CULTURAL and Natural Heritage Russian Federation

The article interprets the complex system of relations between culture and ideology, public and private versions of current ideology, culture, human identity, fragmented state of their mind, etc. Particularly analyzed are the two roles, performed situationally by the individual in the process of sociocultural interactions with the environment - «public person» and "private person.» Here individual culture is treated as a highly theatrical program of behavior, pursuing the goal of maintaining constructive relations with the authorities and the immediate social environment.

We consider the cultural patterns of the man as the immanent forms of internal moral ideology of the individual, culture accepted within the society as a reflection of social interactions among the members of this society, and also the role of culture and ideology in the historical process of evolution, along with the other "locomotives of history» that determine the dynamics of the volatility of social organization within communities.

The main idea of the article is that the culture of a society can be interpreted as a form of the dominant ideology (if we consider the latter not only from the political perspective), but the individual in different social situations, acts with different ideological imperatives. They are usually defined by their roles of «public person» and «private person», with which the phenomenon of the modern human having «multiple identities» is connected, as well as other fragmented manifestations of their consciousness.

Keywords: culture; ideology; public person; private person; multiple identity; ideological fragmentation; professional specialization; reflection of social interactions

\section{REFERENCES}

Bell, D. (1999) Griadushchee postindustrial' noe obshchestvo, transl. by Engl. Moscow, Akademiia. 578 p. (In Russ.).

Gramshi, A. (1959) Izbrannye proizvedeniia: in 3 vol. Moscow, Izdatel'stvo inostrannoi literatury. Vol. 3. 371 p. (In Russ.).

Danilova, E. N. (2005) Sotsial'nye identifikatsii v transformiruiushchemsia obshchestve. In: Sotsial'nye transformatsii $v$ Rossii: teorii, praktiki, sravnitel'nyi analiz, ed. V. A. Iadov. Moscow, Flinta. 583 p. Pp. 324-364. (In Russ.).

Debor, G. (2000) Obshchestvo spektaklia. Moscow, Logos-Radek. 184 p. (In Russ.).

Diurkgeim, E. (1991) O razdelenii obshchestvennogo truda. Metod sotsiologii, transl. by Fr. Moscow, Nauka. 575 p. (In Russ.).

Ideologiia (1952). In: Bol'shaia sovetskaia entsiklopediia: in 51 vol. 2nd ed. Moscow, Sovetskaia entsiklopediia. Vol. 17. 632 p. Pp. 333-337. (In Russ.). 
Klimov, I. E. (2001) Personal'nye mekhanizmy vozniknoveniia krizisa identichnosti. In: Transformatsiia identifikatsionnykh struktur $v$ sovremennoi Rossii, ed. T. G. Stefanenko. Moscow, Moskovskii obshchestvennyi nauchnyi fond. 218 p. Pp. 54-81. (In Russ.).

Malakhov, V. S. (1999) Nostal'giia po identichnosti. Logos, no. 3, pp. 8-12. (In Russ.).

Malygina, I. V. (2002) V labirintakh samoopredeleniia: opyt refleksii na temu etnokul'turnoi identicbnosti. Moscow, MGUKI. 282 p. (In Russ.).

Marks, K. (1959) K kritike politicheskoi ekonomii. In: Marks, K. and Engel's, F. Socbinenia: in 50 vol. 2nd ed. Moscow, IPL. Vol. 13. 765 p. Pp. 1-167. (In Russ.).

Sennet, R. (2002) Padenie publichnogo cheloveka. Moscow, Logos. 424 p. (In Russ.).

Toffler, E. (1997) Futuroshok, transl. by Engl. Moscow, Lan'. 464 p. (In Russ.).

Flier, A. Ia. (2013) Kul'turnye roli v protsessakh sotsial'nogo deistviia. Voprosy kul'turologii, no. 1, pp. 12-19. (In Russ.).

Flier, A. Ia. (2012) Istoriia kul'tury kak smena dominantnykh tipov identichnosti. In: Lichnost'. Kul'tura. Obshchestvo. Vol. 14, issue 1 (69-70), pp. 108-122; issue 2 (69-70), pp. 99-108. (In Russ.).

Flier, A. Ia. (2016) Opyt modelirovaniia kul'tury kak sotsial'noi sistemy. Znanie. Ponimanie. Umenie, no. 2, pp. 113-124. DOI: 10.17805/zpu.2016.2.10 (In Russ.).

Fukuiama, F. (2004) Konets istorii i poslednii chelovek, transl. by Engl. Moscow, AST, Ermak. 488 p. (In Russ.).

Iadov, V. A. (1994) Sotsial'naia identifikatsiia v krizisnom obshchestve. Sotsiologicheskii zburnal, no. 1, pp. 35-52. (In Russ.).

Touraine, A. (1969) La Societé post-industrielle. Naissance d'une société. Paris, Denoël Gonthier. 315 p. (In Fr.).

Submission date: 07.12.2016.

Флиер Андрей Яковлевич - доктор философских наук, профессор, главный научный сотрудник Российского научно-исследовательского института культурного и природного наследия им. А. С. Аихачева. Адрес: 129366, Россия, г. Москва, ул. Космонавтов, д. 2. Тел.: +7 (903) 183-679-45. Эл. aspec: andrey.flier@yandex.ru

Flier Andrei Yakovlevich, Doctor of Philosophy, Professor, chief research scientist, D. S. Likhachev Russian Research Institute for Cultural and Natural Heritage Russian Federation. Postal address: Moscow, 129366, Kosmonavtov St, 2. Tel.: +7 (903) 183-679-45. E-mail: andrey.flier@yandex.ru 